\title{
Bilateral Subthalamic Nucleus Deep Brain Stimulation for Refractory Isolated Cervical Dystonia
}

\author{
Feng Yin ( $\nabla$ yinf897@126.com ) \\ Department of Neurosurgery, Aerospace center hospital \\ Mingming Zhao \\ Department of Neurosurgery, Aerospace center hospital \\ Xin Yan \\ Department of Neurosurgery, Aerospace center hospital \\ Tong Li \\ Department of Neurosurgery, Aerospace center hospital \\ Hui Chen \\ Department of Neurosurgery, Aerospace center hospital \\ Jianguang Li \\ Department of Neurosurgery, Aerospace center hospital \\ Shouming Cao \\ Department of Neurosurgery, Aerospace center hospital \\ Hui Guo \\ Department of Neurosurgery, Aerospace center hospital \\ Shuang Liu \\ Department of Neurosurgery, Aerospace center hospital
}

\section{Research Article}

Keywords: cervical dystonia, subthalamic nucleus, deep brain stimulation, functional neurosurgery

Posted Date: January 4th, 2022

DOI: https://doi.org/10.21203/rs.3.rs-1183056/v1

License: @ (1) This work is licensed under a Creative Commons Attribution 4.0 International License. Read Full License 


\section{Abstract}

Subthalamic nucleus (STN) deep brain stimulation (DBS) has been proven to be an alternative target choice for refractory isolated cervical dystonia (CD). However, assessments of its short and long-term safety, efficacy, and sustained effectiveness have been limited to few reports. Here, we evaluated nine consecutive refractory isolated CD patients who underwent bilateral STN DBS and accepted to short and long-term follow-up in this retrospective study. Seven time points were used to see the Toronto Western Spasmodic Torticollis Rating Scale (TWSTRS) scores (pre-operation [baseline], 1, 3, 6, 12, 24 months postoperation and last follow-up) to assess improvement of dystonic symptoms. The 36-item Short-Form General Health Survey (SF-36) scores obtained at preoperation and last follow-up to assess the changes in quality of life. All patients tolerated surgery well and acquired observable clinical benefits from STN DBS therapy. All patients achieved a considerable improvement in quality of life at the last follow-up. The hardware-related adverse events can be tolerated and the stimulation-related adverse events can be ameliorated by programming. Our data support the idea that bilateral STN DBS is a safety and effective method for the treatment of refractory isolated $\mathrm{CD}$, with persistent and remarkable improvement in both movement and quality of life.

\section{Introduction}

Cervical dystonia (CD), also named spasmodic torticollis, is a focal dystonia that is characterized by sustained or intermittent involuntary contractions of the neck muscles causing turns or tilts in jerky movements or awkward postures of the head ${ }^{1}$. CD is the most common form of focal dystonia, with an approximated prevalence of 28-183 per million people ${ }^{2}$. The complex interaction of motor function impairment, neck pain, and disgrace of CD patients lead to the quality of life reduced seriously due to significant restrictions in daily activities and social participation ${ }^{3-5}$

The conventional treatments of $C D$, which include of oral medication, botulinum toxin injections and physical therapy, are indefinite, causing adverse effects or unsustainable relief of symptoms ${ }^{6}$. Patients have no alternative but to surgical intervention when show resistance to conventional treatment ${ }^{2,7}$.In spite of selective peripheral denervation (SPD) usually gives a satisfactory result in most of the patients, dystonia may recur because of either regeneration of the denervated muscles or disease progression to muscles in the cervical region that were not denervated beforehand ${ }^{7}$. Deep brain stimulation (DBS) has been widely used in the treatment of CD and internal globus pallidus (GPi) is the most prevalently used target, its safety and efficacy have been validated ${ }^{8}$, but stimulation-induced side effects are common and insurmountable ${ }^{9}$. Its high-energy consumption is another drawback ${ }^{10}$. The effectiveness of subthalamic nucleus (STN) stimulation has shown to be an alternative target choice in the treatment for isolated CD, but only displayed in a few of studies ${ }^{11,12}$.

In this retrospective study, we explore the effect of bilateral STN DBS on safety, efficacy, sustainability and quality of life in a series of patients with refractory isolated $\mathrm{CD}$

\section{Methods}

\section{Subjects}

This study was conducted in accordance with the Declaration of Helsinki 1964 (2013 revision) and performed at the Chinese PLA General Hospital-Sixth Medical Center and approved by the ethics committees. All of the patients and their family assent to this trial and signed the informed consent form. Between September 2014 and June 2018, nine consecutive patients with refractory isolated CD who had undergone bilateral STN DBS at our center were eligible to participate in the study. Inclusion criteria were: a diagnosis of isolated predominantly CD; severe functional impairment and failed to respond to oral pharmacotherapy, botulinum toxin or selective peripheral denervation (SPD); absence of secondary causes including neuroleptic treatment before dystonia onset; normal neurologic examination except for dystonia and normal brain MRI; and willing to accept regular consulting visits and a long-term follow up. Exclusion criteria were: a medical contraindication to surgery; evidence on MRI of another neurologic disorder or extensive brain atrophy or anatomical anomalies in the basal ganglia region; severe cognitive impairment or depression, severe psychiatric disease.

\section{Surgical procedures}

All operations were accomplished by the same two skillful neurosurgeons and the surgical technique was similar to previously described ${ }^{33}$. The dorsal regions of bilateral STN were chosen as the targets which were determined directly by T2 MRI or by fusing 3T MRI (T1/T2 sequences) obtained a day before the surgery with high-resolution CT (scanned with a Leksell stereotactic frame). Quadripolar DBS leads, which had four contacts (contact width of 1.5 mm, diameter of $1.3 \mathrm{~mm}$ and the gap between two adjacent contacts is $0.5 \mathrm{~mm}$ ), were implanted guided by microelectrode recording under local anesthesia, and then connected to a dual channel neurostimulator implanted in the right subclavicular pocket under general anaesthesia (devices model see Table 1). All patients experienced post-operative brain CT scan to rule out haemorrhage (Fig. 2a). Post-operative electrodes positions were identified by MRI scan (Fig. 2b) or by fusing post-operative high-resolution CT images with the pre-operative MRI.

\section{Post-operative programming}

Programming was initiated 3 weeks after DBS surgery. Each contact was activated in monopolar stimulation and constant-voltage stimulus mode respectively, with pulse width, frequency and amplitude of $60 \mathrm{us}, 130 \mathrm{~Hz}$ and 1.5-2V, respectively. The treatment responses and side effects were observed and recorded. The contact chosen at initial programming was the one clinical improvement relatively significant and would allow for the increase amplitude in increments of $0.05 \mathrm{~V}$ to $0.1 \mathrm{~V}$ per week without stimulation-induced adverse events (with the exception of dyskinesia). Initial amplitude set between $1.0 \mathrm{~V}$ and $1.5 \mathrm{~V}$ and then slowly increased by the patient in the following time to further treat the dystonia. If dyskinesia occurred, patients were instructed to slightly decrease the amplitude and then slowly increased. If symptoms improvement was not desirable at amplitude of $3.0 \mathrm{~V}$ or stimulation-induced adverse events limited the increase in amplitude, the patient was reprogrammed by doctor using an additional dorsal contact, even bipolar stimulation or constant-current stimulus mode were tried. 


\section{Clinical evaluation}

Dystonic symptoms were evaluated by an independent movement disorder neurologist at pre-operation [baseline] and post-operation [short-term follow-up: 1, 3, 6 and 12 months after neurostimulator turned on; long-term follow-up: 24 months and last follow-up], according to the Toronto Western Spasmodic Torticollis Rating Scale (TWSTRS) ${ }^{34}$, which contains three sections, a severity score (0-35), a disability score (0-30), and a pain score (0-20). Higher scores represent greater impairment. The 36-item Short-Form General Health Survey (SF-36) ${ }^{35}$ was used to evaluate their health-related quality of life at baseline and the last follow-up, which includes eight aspects of the health condition of each patient, with the score for each section ranging from 0 (worst) to 100 (best), and higher scores indicate better daily function and condition.

\section{Statistical methods}

SPSS version 19.0 (SPSS, Inc., Chicago, IL, USA) was used for statistical analyses. The Shapiro-Wilk test was applied to analyze the distribution of the grouped data. The two tailed paired-sample t-tests was used to compare baseline and follow-up TWSTRS scores (severity, disability, pain, and total) and SF-36 scores if the data were distributed normally. If not, the Wilcoxon matched-pairs signed-rank test was performed. Correlations between the final improvement in the TWSTRS severity subscores and the relevant variables were analyzed by using Spearman correlation (for quantitative variables) or the Mann-Whitney test (for categorical variables). Two-tailed $p<0.05$ were considered statistically significant. The results are presented as mean \pm SD.

\section{Results}

Patient demographics are shown in Table 1. Nine patients ( 3 men and 6 women) were enrolled in the study. The mean age of onset and duration of disease were $40.9 \pm 12.3$ (18-62) years and $4.1 \pm 2.5$ (range 1.5-9) years, respectively. The average age at surgery was $44.9 \pm 11.9$ (range $27-69$ ) years, and the mean follow-up time was $46.6 \pm 15.8$ (range 24-68) months (Table 1). All patients received bilateral STN DBS and complete the 24 months visit. All patients had prominent $C D$. Some dystonia was also present in other body regions in 3 patients, but the symptoms were mild. Only one patient received battery replacement 42 months after DBS due to battery depletion. Before DBS, the average TWSTRS severity, disability, and pain subscores and total scores were $22.4 \pm 3.2$ (range 19.0-28.0), $19.3 \pm 3.9$ (range 13.0-25.0), $6.1 \pm 4.4$ (range 0-12.0), and 47.9 \pm 9.5 (range 32.0-60.0), respectively (Table 2 and 3 ).

\section{Clinical outcomes}

Effects of DBS on TWSTRS scores are detailed in the Table 2. Compared to baseline scores, the mean improvements in the TWSTRS severity scores were $21.8 \% \pm 10.9 \%$ (range $9.5 \%-36.8 \% ; p=0.001$ ) at 1 month postsurgery, $55.5 \% \pm 18.1 \%$ (range $28.6 \%-88.5 \% ; p<0.001$ ) at 3 months postsurgery, $74.4 \% \pm 27.2 \%$ (range $21.4 \%-100 \% ; p<0.001$ ) at 6 months postsurgery, $87.4 \% \pm 25.3 \%$ (range $25.0 \%-100 \% ; p=0.007$ ) at 12 months postsurgery, $86.2 \% \pm 30.5 \%$ (range $7.1 \%-100 \% ; p=0.007)$ at 24 months postsurgery, and $96.2 \% \pm 8.5 \%$ (range $75.0 \%-100 \% ; p=0.007$ ) at the last follow-up. Similar improvements were seen in the TWSTRS total scores, with $22.2 \% \pm 11.7 \%$ (range $11.5 \%-37.5 \% ; p=0.001$ ) at 1 month postsurgery, $55.3 \% \pm 20.3 \%$ (range $16.7 \%-82.5 \%$; $p<0.001$ ) at 3 months postsurgery, $74.3 \% \pm 29.8 \%$ (range $13.3 \%-100 \% ; p=0.008$ ) at 6 months postsurgery, $87.2 \% \pm 27.0 \%$ (range $20.0 \%-100 \%$; $p=0.008$ ) at 12 months postsurgery, $87.3 \% \pm 29.6 \%$ (range $10 \%-100 \% ; p=0.008$ ) at 24 months postsurgery, and $96.6 \% \pm 8.3 \%$ (range $75.0 \%-100 \% ; p=0.008$ ) at the last follow-up (Table 3 and Fig. 1a).

Compared to baseline scores, the mean improvements in the TWSTRS disability scores were $21.0 \pm 14.1$ (range $5.0 \%-40.0 \%$; $p=0.002$ ) at 1 month postsurgery, $52.9 \pm 25.3$ (range $4.0 \%-80.0 \% ; p<0.001$ ) at 3 months postsurgery, $73.3 \pm 33.9$ (range $4.0 \%-100 \% ; p=0.007$ ) at 6 months postsurgery, $86.3 \pm 29.6$ (range $12.0 \%-100 \% ; p=0.008$ ) at 12 months postsurgery, $88.1 \pm 30.2$ (range $8.0 \%-100 \% ; p=0.008$ ) at 24 months postsurgery, and $97.2 \pm 6.7$ (range $80.0 \%-100 \% ; p=$ 0.007 ) at the last follow-up (Table 3 and Fig. 1a). We also observed significant improvements postoperatively compared to baseline in the TWSTRS pain scores (Table 3).

Patient-5 is a special case, whose dystonic symptom with diurnal fluctuations and paroxysmal and improved poor under constant-voltage stimulus. When converted to a constant current stimulus, the symptoms gradually improved and relatively satisfactory results were obtained at the last follow up (Figs. $1 \mathrm{~b}, 1 \mathrm{c})$.

The quality of life was also improved significantly for all the patients at the last follow-up. Changes in SF-36 scores after chronic stimulation reflect this improvement (Table 4 and Fig. 1d).

\section{Predictors for movement improvement}

We assessed correlations between the final TWSTRS severity improvement and baseline factors, as well as duration of stimulation. However, there were no significant predictors for long-term movement improvement (sex, $p=0.714$; type of dystonic movement, $p=1.0$; age at disease onset, $p=0.513$; duration of disease, $p=0.558$; age at surgery, $p=0.507$; duration of stimulation, $p=0.332$; baseline TWSTRS severity, $p=0.206$ ).

\section{Stimulation parameters}

The stimulation parameters were shown in Table 2. Post-operative imaging confirmed all of electrodes were implanted near the predetermined location (central in the dorsal STN). A total of 18 DBS electrodes were placed in 9 patients and all used monopolar stimulus mode. At the last follow-up visit, the mean pulse width was $60.7 \pm 2.3$ us, the mean frequency was $134.3 \pm 6.5 \mathrm{~Hz}, 8$ patients using constant-voltage stimulation (mean amplitude was $2.3 \pm 0.6 \mathrm{~V}$ ) and one patient using constant-current stimulation (bilateral $2.4 \mathrm{~mA}$ ). At initial programming phase, $77.8 \%(7 / 9)$ patients had an immediate response within a matter of hours to days, manifested as amelioration of motor symptoms, relaxation of neck muscles, or relief of pain. When the symptom improvement got the stable 
phase, patient- 1 reduced amplitude from $2.0 \mathrm{~V}$ to $1.0 \mathrm{~V}$ for two years and patient-2 reduce amplitude from $3.5 \mathrm{~V}$ to $2.5 \mathrm{~V}$ for half a year, all of them maintained a steady improvement as before.

\section{Adverse events}

There were no serious adverse events related to the surgical procedure (for example: intracranial hemorrhages or device infections) in all patients during the follow-up. The uncomfortable tensor sensation near the extension wire was experienced in 4 patients caused by the extension wire, but no patient needed additional surgery. One patient experienced mild pain sometimes at the neurostimulator site, but it had no practical impact on her daily living. One patient experienced mild balance disturbances, two patients experienced mild hand weakness and eight patients experienced dyskinesia, all of them were alleviated by programming.

\section{Discussion}

The present study established the safety, efficacy, and reliability of STN DBS for the treatment of refractory isolated CD. The results showed that patients attained persisting and substantial improvement of various dystonic manifestations and the quality of life.

Unlike other study reported ${ }^{11}$, we did not observed obvious micro-lesions effect just like Parkinson's disease after DBS. The improvement on the TWSTRS total score was $22.2 \% \pm 11.7 \%$ at 1 month after STN-DBS for CD, but more than $50 \%$ for primary dystonia (including varied subtypes) ${ }^{13,14}$. The lower improvement degree may be related to two reasons. The first, we usually used lower amplitude (1.5 V-2.0 V) in the first month after neurostimulator initiated for avoided the side effects, which may not get the ideal treatment threshold. The second, CD only involves cervical symptoms, which is different from segmental, multifocal or generalized dystonia involving multiple parts of the body. As the increase of amplitude, the improvement reached $55.3 \% \pm 20.3 \%$ by the 3 -month visit, similar to that previously reported in the follow-up study of primary CD patients treated with STN DBS (50.6\%) ${ }^{12}$. To our surprise, after 6 and 12 months of STN stimulation, the improvement reached $74.3 \% \pm 29.8 \%$ and $87.2 \% \pm 27.0 \%$, respectively, which were superior to that previously report showed an improvement of $60.2 \%$ and $62.9 \%$ at the corresponding point in time ${ }^{12}$.

The long-term improvement was more remarkable and superior to previously study of idiopathic predominantly CD treated with STN DBS ${ }^{15}$. A study of STN DBS in the treatment of primary dystonia also showed similar surprising results, with an average improvement rate of $85.0 \%$ in BFMDRS-M at 1 year, $90.8 \%$ at 5 years and $91.4 \%$ at the last follow-up ${ }^{14}$. Ultimately, the quality of life in all patients improved significantly, as reflected in the SF-36 assessment. No matters in physical or mental aspects, dystonia symptoms were the main reason for the decline of quality of life. Therefore, with the significant improvement of dystonia symptoms after STN DBS, the patients get rid of the trouble and disgrace of the disease, resume normal daily activities and social participation, and enhance their confidence in life.

The target choice of GPi or STN is still controversial in treatment of dystonia and the former is more popular up to now. Although some control studies shown no statistical difference between the two targets in the treatment of primary dystonia ${ }^{10,16}$, however, the reliability of this conclusion was questionable due to the shorter follow-up time, limited sample size and different subtypes of dystonia. Actually, convergent evidence now suggests that CD is a 'network disorder' resulting from dysfunction in multiple different brain regions, and the abnormal connectivity between cerebellar and somatosensory has been confirmed ${ }^{17}$. STN plays a pivotal role in the motor regulation of the cortico-basal ganglia-cerebellar connectome via indirect, hyperdirect and STN-ponto-cerebellar cortex pathway ${ }^{18}$. The hyperdirect pathway is faster than the striatal pathways ${ }^{19}$. Thus, STN DBS theoretically is more effective and quicker than GPi DBS in the treatment of dystonia. Obviously, our results showed that the effects of STN DBS seemed to be dramatically superior to those of GPi DBS for isolated CD 8,20 . The trend to maintain the symptoms improvement continues at one year and beyond after STN DBS is incomparable for GPi ${ }^{20}$. The response after STN stimulation is immediate in most patients, which can provide clues for selecting the optimal stimulus contact and parameters. The same phenomenon was observed by other authors ${ }^{11,14}$. This advantage over GPi-DBS is conducive to improving the efficiency and quality of programming, making patients full of confidence and obtaining satisfactory experience. In present study, the parameters of stimulation were significantly lower than those of GPi stimulation $20,21$. Therefore, another advantage of STN over GPi is longer battery life.

Previous studies on the treatment of primary CD with GPi DBS have reported that some of them present bradykinesia and axial motor symptoms ${ }^{22,23}$, and dysarthria is another most common stimulation-induced side effect with a prevalence estimated up to $12 \%{ }^{24}$. In general, these problems cannot be solved through programming changes without sacrificing dystonia improvement. By comparison, no patients reported slowing of motor function and dysarthria in the present series. Dyskinesia is a temporary side effect and easily induced by voltage-limiting stimulation, which typically improved by programming changes without losing clinical benefit. Dyskinesia can usually be minimized or avoided by decelerate the rate at which the amplitude was increased in the STN or activating the contact located more dorsal STN. Although no side effects such as dysarthria, dysphoria, anxiety, depression, dysphasia, numbness, paresthesia, or pain occurred in our study, they have been reported previously ${ }^{15}$. This may be attributable to the smaller size and topological organization of the STN, without well-defined anatomical boundaries and instead a degree of overlap between functional zones ${ }^{25}$. This means that stimulation can more easily affect internal non-motor functional areas and external surrounding tissues. Therefore, accurate electrode position, ideal active contact selection and reasonable programming are especially important.

In our experience, the ideal position for electrode implantation is the central of the dorsal STN and the optimal stimulation points is the area above the STN (including the $\mathrm{Zi}$ and Forel $\mathrm{H} 2$ ), which is similar to treating Parkinson's disease and confirmed again by a study using directional leads ${ }^{26}$. We found that patient's self-adjustment under the supervision of the treating physician is an advanced DBS programming strategy, feasible, practical and significantly shorten consultation time in dystonia patients. It was not easy to supervise patients who were far away from treatment center, so that they could not reprogram in time, then affected the treatment effectiveness. Fortunately, the modified DBS system which can offer video communication and remote

Page $4 / 10$ 
programming function allowing doctors to learn about the treatment effect timely, select optimal active contacts and adjust appropriate stimulation parameters for patients and significantly promote the efficiency of programming.

An unusual case, patient- 5 had an uncommon clinical characteristic, marked diurnal fluctuation and paroxysmal, had poor symptom improvement within 2 year after surgery. The unexpected thing was that paroxysmal dystonia symptom disappeared immediately after converted constant-voltage stimulation to constant-current stimulation without a change in active contact. It seems that constant-current stimulation can relieve paroxysmal dystonia symptom, which may be related to its ability to offer more stable stimulation ${ }^{27}$. This was just an isolated case and further attempts are necessary.

A new finding in present study was that when the symptom improvement get the stable phase, the appropriate amplitude reduction will not affect the therapeutic effect and will be maintained with lower stimulus parameters, this we called "Top-Down" rule (e.g. patient-1 and 2). Some studies reported that cessation of STN stimulation does not aggravate dystonia ${ }^{14,28,29}$, but our patient-7 turned off the stimulator inadvertently leaded to partly relapse and then returned to normal when turned on. Therefore, we suggest that a modest reduction of the stimulation amplitude when get the stable phase can save stimulator power, reduce the side effects of stimulation and maintain the therapeutic effect, but not recommended to turn off the stimulator or reduce the amplitude when the symptom improvement is not reach the stable phase.

The predictive factors associated with outcome of DBS are also one of the hottest topics in discussion. Some long term outcome studies of STN and dystonia have shown that the degree of improvement is related to duration of the disease before surgery ${ }^{13}$ and age at surgery ${ }^{15}$. In present series, the long-term outcome seemed to be not associated with age at disease onset, disease duration, sex, type of dystonic movement, age at surgery, duration of stimulation, and baseline TWSTRS severity.

The primary device-related adverse event in our study was uncomfortable tensor sensation near the extension wire, which has been reported ${ }^{30}$. The extension wire after DBS even trigger painful CD, deeper channeling of the wire extensions produced a complete remission ${ }^{31}$. Discomfort around neurostimulator is another reported device-related adverse event, which related to the size of neurostimulator ${ }^{15}$. Future advances in materials and technological improvement may allow patients have a better treatment experience.

Several limitations were existed in present study. First, this is a single-center non-blinded retrospective study and the results are limited to our relatively small sample size and patient selection. Although all patients had prominent cervical involvement, three patients also had other body regions affected. Thus, large controlled multicenter double-blinded are needed to identify whether the observed strong therapeutic effects of STN-DBS can be confirmed in other research settings, in other samples of patients with refractory isolated CD. Furthermore, none of the patients underwent genetic testing. CD has a complex genetic background ${ }^{32}$, with various underlying causes. Identification of genetic variations associated with CD may conducive to understand the association with treatment.

Conclusions: The present retrospective study found that the vast majority of patients with refractory isolated CD can obtain enormous benefits in the aspect of reduction in dystonic symptoms and improvement in quality of life after bilateral STN DBS. The improvement of individual patient has a tortuous process. Therefore, large controlled multicenter double-blinded trials are warranted to identify these observations on account of the small sample size of the current study. Most importantly, the therapy expatiated here seems to be a safety, effective and stable method, but further follow-up is required.

\section{Declarations}

Acknowledgments We would like to thank our Excellent nurses and anesthesiologists, without whom we couldn't have done DBS surgery well.

Authors' contributions All authors contributed to the study conception and design. Feng Yin: conception and design of the work; data acquisition; analysis and interpretation of data; revision of manuscript. Mingming Zhao: data acquisition; draft of manuscript. Xin Yan: data acquisition; draft and revision of manuscript. Tong li, Hui Chen, Jianguang Li ,Shouming Cao, Hui Guo and Shuang Liu provided critical feedback and helped shape the manuscript.

Competing interests The authors declare that they have no conflict of interest.

Funding This work was supported by the Capital Clinical Characteristic Cpplication Research and the Achievement Promotion Topic Sub-topic No. z151100004015219.

Ethiacl approval Ethics approval/consent to participate/consent for publication.

Informed consent All patients gave their written informed consent to surgery, the study and the publication of results.

\section{References}

1. Albanese, A. et al. Phenomenology and classification of dystonia: a consensus update. Mov Disord 28, 863-873, doi:10.1002/mds.25475 (2013).

2. Albanese, A. Deep brain stimulation for cervical dystonia. Lancet Neurol 13, 856-857, doi:10.1016/S1474-4422(14)70178-4 (2014).

3. Jankovic, J., Tsui, J. \& Bergeron, C. Prevalence of cervical dystonia and spasmodic torticollis in the United States general population. Parkinsonism Relat Disord 13, 411-416, doi:10.1016/j.parkreldis.2007.02.005 (2007).

4. Nutt, J. G., Muenter, M. D., Aronson, A., Kurland, L. T. \& Melton, L. J., 3rd. Epidemiology of focal and generalized dystonia in Rochester, Minnesota. Mov Disord 3, 188-194, doi:10.1002/mds.870030302 (1988). 
5. Ben-Shlomo, Y., Camfield, L., Warner, T. \& group, E. c. What are the determinants of quality of life in people with cervical dystonia? J Neurol Neurosurg Psychiatry 72, 608-614, doi:10.1136/jnnp.72.5.608 (2002).

6. Swope, D. \& Barbano, R. Treatment recommendations and practical applications of botulinum toxin treatment of cervical dystonia. Neurol Clin 26 Suppl 1 , 54-65, doi:10.1016/s0733-8619(08)80005-9 (2008).

7. Bergenheim, A. T., Nordh, E., Larsson, E. \& Hariz, M. I. Selective peripheral denervation for cervical dystonia: Iong-term follow-up. J Neurol Neurosurg Psychiatry 86, 1307-1313, doi:10.1136/jnnp-2014-307959 (2015).

8. Hung, S. W. et al. Long-term outcome of bilateral pallidal deep brain stimulation for primary cervical dystonia. Neurology $68,457-459$, doi:10.1212/01.wnl.0000252932.71306.89 (2007).

9. Mahlknecht, P. et al. Parkinsonian signs in patients with cervical dystonia treated with pallidal deep brain stimulation. Brain 141, 3023-3034, doi:10.1093/brain/awy217 (2018).

10. Lin, S. et al. Deep brain stimulation of the globus pallidus internus versus the subthalamic nucleus in isolated dystonia. J Neurosurg, 1-12, doi:10.3171/2018.12.JNS181927 (2019).

11. Pahapill, P. A. \& O'Connell, B. Long-term follow-up study of chronic deep brain stimulation of the subthalamic nucleus for cervical dystonia. Neuromodulation 13, 26-30, doi:10.1111/j.1525-1403.2009.00231.x (2010).

12. Ostrem, J. L. et al. Subthalamic nucleus deep brain stimulation in primary cervical dystonia. Neurology 76, 870-878, doi:10.1212/WNL.0b013e31820f2e4f (2011).

13. Cao, C. et al. Subthalamus deep brain stimulation for primary dystonia patients: a long-term follow-up study. Mov Disord 28, 1877-1882, doi:10.1002/mds.25586 (2013).

14. Deng, Z. et al. Subthalamic deep brain stimulation in patients with primary dystonia: A ten-year follow-up study. Parkinsonism Relat Disord 55, 103-110, doi:10.1016/j.parkreldis.2018.05.024 (2018).

15. Ostrem, J. L. et al. Subthalamic nucleus deep brain stimulation in isolated dystonia: A 3-year follow-up study. Neurology $88,25-35$, doi:10.1212/WNL.0000000000003451 (2017).

16. Schjerling, L. et al. A randomized double-blind crossover trial comparing subthalamic and pallidal deep brain stimulation for dystonia. J Neurosurg 119 , 1537-1545, doi:10.3171/2013.8.JNS13844 (2013).

17. Corp, D. T. et al. Network localization of cervical dystonia based on causal brain lesions. Brain 142, 1660-1674, doi:10.1093/brain/awz112 (2019).

18. Quartarone, A. et al. New insights into cortico-basal-cerebellar connectome: clinical and physiological considerations. Brain 143, 396-406, doi:10.1093/brain/awz310 (2020).

19. Hazrati, L. N. \& Parent, A. Convergence of subthalamic and striatal efferents at pallidal level in primates: an anterograde double-labeling study with biocytin and PHA-L. Brain Res 569, 336-340, doi:10.1016/0006-8993(92)90648-s (1992).

20. Walsh, R. A. et al. Bilateral pallidal stimulation in cervical dystonia: blinded evidence of benefit beyond 5 years. Brain 136, 761-769, doi:10.1093/brain/awt009 (2013).

21. Kiss, Z. H. et al. The Canadian multicentre study of deep brain stimulation for cervical dystonia. Brain 130, 2879-2886, doi:10.1093/brain/awm229 (2007).

22. Reese, R. et al. Full Parkinsonian Triad Induced by Pallidal High-Frequency Stimulation in Cervical Dystonia. Mov Disord Clin Pract 2, 99-101, doi:10.1002/mdc3.12105 (2015).

23. Huebl, J. et al. Bradykinesia induced by frequency-specific pallidal stimulation in patients with cervical and segmental dystonia. Parkinsonism Relat Disord 21, 800-803, doi:10.1016/j.parkreldis.2015.04.023 (2015).

24. Kupsch, A. et al. Pallidal deep-brain stimulation in primary generalized or segmental dystonia. N Engl J Med 355, 1978-1990, doi:10.1056/NEJMoa063618 (2006).

25. Haynes, W. I. \& Haber, S. N. The organization of prefrontal-subthalamic inputs in primates provides an anatomical substrate for both functional specificity and integration: implications for Basal Ganglia models and deep brain stimulation. J Neurosci 33, 4804-4814, doi:10.1523/JNEUROSCI.4674-12.2013 (2013).

26. Koeglsperger, T., Palleis, C., Hell, F., Mehrkens, J. H. \& Botzel, K. Deep Brain Stimulation Programming for Movement Disorders: Current Concepts and Evidence-Based Strategies. Front Neurol 10, 410, doi:10.3389/fneur.2019.00410 (2019).

27. Beaulieu-Boire, I. \& Fasano, A. Current or voltage? Another Shakespearean dilemma. Eur J Neuro/ 22, 887-888, doi:10.1111/ene.12537 (2015).

28. Deng, Z. D. et al. Long-term follow-up of bilateral subthalamic deep brain stimulation for refractory tardive dystonia. Parkinsonism Relat Disord 41, 58-65, doi:10.1016/j.parkreldis.2017.05.010 (2017).

29. Meng, D. W., Liu, H. G., Yang, A. C., Zhang, K. \& Zhang, J. G. Long-term Effects of Subthalamic Nucleus Deep Brain Stimulation in Tardive Dystonia. Chin Med J (Engl) 129, 1257-1258, doi:10.4103/0366-6999.181977 (2016).

30. Wachter, T. et al. Severe muscular fasciculations as an uncommon side-effect due to microdefect of an extension wire in deep brain stimulation. Mov Disord 24, 2161-2162, doi:10.1002/mds.22725 (2009).

31. Spagnolo, F. et al. Painful cervical dystonia triggered by the extension wire of a deep brain stimulator. J Clin Neurosci 19, 1582-1583, doi:10.1016/j.jocn.2011.11.040 (2012).

32. Groen, J. L. et al. Cervical dystonia and genetic common variation in the dopamine pathway. Parkinsonism Relat Disord 19, 346-349, doi:10.1016/j.parkreldis.2012.08.016 (2013). 
33. Starr, P. A. et al. Implantation of deep brain stimulators into the subthalamic nucleus: technical approach and magnetic resonance imaging-verified lead locations. J Neurosurg 97, 370-387, doi:10.3171/jns.2002.97.2.0370 (2002).

34. Kaji, R., Osawa, M. \& Yanagisawa, N. [Inter-rater reliability while using the Toronto Western Spasmodic Torticollis Rating Scale (TWSTRS) in patients with cervical dystonia]. Brain Nerve 61, 65-71 (2009).

35. Ware, J. E., Jr. \& Sherbourne, C. D. The MOS 36-item short-form health survey (SF-36). I. Conceptual framework and item selection. Med Care 30, 473-483 (1992).

\section{Tables}

\begin{tabular}{|c|c|c|c|c|c|c|c|c|c|c|c|}
\hline $\begin{array}{l}\text { Patient } \\
\text { No. }\end{array}$ & Sex & $\begin{array}{l}\text { Age } \\
\text { at } \\
\text { onset } \\
\text { (yrs) }\end{array}$ & $\begin{array}{l}\text { Duration } \\
\text { of } \\
\text { disease } \\
\text { (yrs) }\end{array}$ & $\begin{array}{l}\text { Site of } \\
\text { onset }\end{array}$ & $\begin{array}{l}\text { Baseline } \\
\text { distribution } \\
\text { of dystonia }\end{array}$ & $\begin{array}{l}\text { Type of } \\
\text { dystonic } \\
\text { movement }\end{array}$ & $\begin{array}{l}\text { Age at } \\
\text { DBS } \\
\text { surgery } \\
\text { (yrs) }\end{array}$ & $\begin{array}{l}\text { Duration } \\
\text { of } \\
\text { follow- } \\
\text { up } \\
\text { (mos) }\end{array}$ & $\begin{array}{l}\text { Treatment } \\
\text { before DBS }\end{array}$ & $\begin{array}{l}\text { DBS lead } \\
\text { model }\end{array}$ & $\begin{array}{l}\text { Neurostimula } \\
\text { model }\end{array}$ \\
\hline 1 & $\mathrm{~F}$ & 42 & 1.5 & Cervical & Neck & Tonic & 43 & 68 & $\begin{array}{l}\text { Carbamazepine, } \\
\text { TCM }\end{array}$ & $\begin{array}{l}\text { L301 } \\
\text { (PINS) }\end{array}$ & G101A \\
\hline 2 & $\mathrm{~F}$ & 30 & 3 & Cervical & Neck & Phasic & 33 & 60 & $\begin{array}{l}\text { TCM, botulinum } \\
\text { toxin, SPD }\end{array}$ & $\begin{array}{l}\text { L301 } \\
\text { (PINS) }\end{array}$ & G102 \\
\hline 3 & $M$ & 42 & 3 & Cervical & Neck & Tonic & 45 & 60 & $\begin{array}{l}\text { Baclofen, } \\
\text { botulinum toxin }\end{array}$ & $\begin{array}{l}\text { L301 } \\
\text { (PINS) }\end{array}$ & G102 \\
\hline 4 & $\mathrm{~F}$ & 45 & 2 & Cervical & Neck & Phasic & 47 & 54 & TCM, baclofen & $\begin{array}{l}33895 \\
\text { (Medtronic) }\end{array}$ & $\mathrm{RC}$ \\
\hline 5 & M & 40 & 3 & Cervical & Neck/Eyes/Mouth & Phasic & 43 & 51 & $\begin{array}{l}\text { Tiapride, } \\
\text { haloperidol, } \\
\text { alprazolam, } \\
\text { clonazepam, } \\
\text { baclofen }\end{array}$ & $\begin{array}{l}\text { L301 } \\
\text { (PINS) }\end{array}$ & G102R \\
\hline 6 & $\mathrm{~F}$ & 18 & 9 & Cervical & Neck/Arm/Foot & Phasic & 27 & 43 & $\begin{array}{l}\text { TCM, botulinum } \\
\text { toxin, } \\
\text { clonazepam, } \\
\text { quetiapine, L- } \\
\text { levodopa, SPD }\end{array}$ & $\begin{array}{l}\text { L301 } \\
\text { (PINS) }\end{array}$ & G102R \\
\hline 7 & $M$ & 51 & 3 & Eyes & Neck/Eyes/Mouth & Tonic & 54 & 30 & $\begin{array}{l}\text { Clonazepam, } \\
\text { baclofen }\end{array}$ & $\begin{array}{l}\text { L301 } \\
\text { (PINS) }\end{array}$ & G102R \\
\hline 8 & $\mathrm{~F}$ & 38 & 5 & Cervical & Neck & Phasic & 43 & 29 & $\begin{array}{l}\text { Clonazepam, } \\
\text { trihexyphenidyl, } \\
\text { botulinum toxin }\end{array}$ & $\begin{array}{l}\text { L301 } \\
\text { (PINS) }\end{array}$ & G102 \\
\hline 9 & $\mathrm{~F}$ & 62 & 7 & Cervical & Neck & Tonic & 69 & 24 & $\begin{array}{l}\text { Baclofen, } \\
\text { trihexyphenidy }\end{array}$ & $\begin{array}{l}\text { L301 } \\
\text { (PINS) }\end{array}$ & G102RZ \\
\hline $\begin{array}{l}\text { Mean } \\
\pm S D\end{array}$ & & $\begin{array}{l}40.9 \\
\pm \\
12.3\end{array}$ & $4.1 \pm 2.5$ & & & & $\begin{array}{l}44.9 \pm \\
11.9\end{array}$ & $\begin{array}{l}46.6 \pm \\
15.8\end{array}$ & & & \\
\hline
\end{tabular}

Table 1. Clinical characteristics and DBS devices model for each patient with isolated cervical dystonia. DBS-deep brain stimulation, F-Female, M-male, SPDselective peripheral denervation, TCM-traditional Chinese medicine, SD-standard deviation, yrs-years, mos-months. 


\begin{tabular}{|c|c|c|c|c|c|c|c|c|}
\hline \multirow{2}{*}{$\begin{array}{l}\text { Patient } \\
\text { No. }\end{array}$} & \multicolumn{7}{|c|}{ TWSTRS (Severity/Disability/Pain Subscale Scores) } & \multirow{2}{*}{$\begin{array}{l}\text { Stimulation parameters at last } \\
\text { follow-up }\end{array}$} \\
\hline & Baseline & Month 1 & Month 3 & Month 6 & Month 12 & Month 24 & $\begin{array}{l}\text { Last follow- } \\
\text { up }\end{array}$ & \\
\hline \multirow[t]{2}{*}{1} & $\begin{array}{l}39(20 / 16 / \\
\text { 3) }\end{array}$ & $\begin{array}{l}30.5 \\
(16 / 12 / 2.5)\end{array}$ & $14(6 / 7 / 1)$ & $3(2 / 1 / 0)$ & $0(0 / 0 / 0)$ & $0(0 / 0 / 0)$ & $0(0 / 0 / 0)$ & $\begin{array}{l}\text { Left:1.0V/130Hz/60us case (+) } 6 \\
(-)\end{array}$ \\
\hline & & & & & & & & $\begin{array}{l}\text { Right:1.0V/130Hz/60us case }(+) 2 \\
(-)\end{array}$ \\
\hline \multirow[t]{2}{*}{2} & $\begin{array}{l}57 \\
(26 / 22 / 9)\end{array}$ & $36(17 / 14 / 5)$ & $10(3 / 5 / 2)$ & $0(0 / 0 / 0)$ & $0(0 / 0 / 0)$ & $0(0 / 0 / 0)$ & $0(0 / 0 / 0)$ & $\begin{array}{l}\text { Left:2.5V/140Hz/60us case (+) } 5 \\
(-)\end{array}$ \\
\hline & & & & & & & & $\begin{array}{l}\text { Right:2.5V/140Hz/60us case (+) } 1 \\
(-)\end{array}$ \\
\hline \multirow[t]{2}{*}{3} & $\begin{array}{l}51 \\
(24 / 20 / 7)\end{array}$ & $43(19 / 18 / 6)$ & $\begin{array}{l}31 \\
(13 / 15 / 3)\end{array}$ & $\begin{array}{l}25 \\
(10 / 12 / 3)\end{array}$ & $15(7 / 6 / 2)$ & $9(5 / 2 / 2)$ & $0(0 / 0 / 0)$ & $\begin{array}{l}\text { Left:2.9V/132Hz/60us case (+) } 7 \\
(-)\end{array}$ \\
\hline & & & & & & & & $\begin{array}{l}\text { Right:2.5V/132Hz/70us case }(+) 1 \\
(-)\end{array}$ \\
\hline \multirow[t]{2}{*}{4} & $\begin{array}{l}41 \\
(20 / 15 / 6)\end{array}$ & $36(18 / 13 / 5)$ & $9(6 / 3 / 0)$ & $0(0 / 0 / 0)$ & $0(0 / 0 / 0)$ & $0(0 / 0 / 0)$ & $0(0 / 0 / 0)$ & $\begin{array}{l}\text { Left:2.7V/150Hz/60us case (+) } 7 \\
(-)\end{array}$ \\
\hline & & & & & & & & $\begin{array}{l}\text { Right:2.8V/150Hz/60us case }(+) 3 \\
(-)\end{array}$ \\
\hline \multirow[t]{2}{*}{5} & $\begin{array}{l}60 \\
(28 / 25 / 7)\end{array}$ & $51(22 / 23 / 6)$ & $\begin{array}{l}50 \\
(20 / 24 / 6)\end{array}$ & $\begin{array}{l}52 \\
(22 / 24 / 6)\end{array}$ & $\begin{array}{l}48 \\
(21 / 22 / 5)\end{array}$ & $\begin{array}{l}54 \\
(26 / 23 / 5)\end{array}$ & $15(7 / 5 / 3)$ & $\begin{array}{l}\text { Left:2.4mA/130Hz/60us case (+) } \\
5(-)\end{array}$ \\
\hline & & & & & & & & $\begin{array}{l}\text { Right:2.4mA/130Hz/60us case }(+) \\
4(-)\end{array}$ \\
\hline \multirow[t]{2}{*}{6} & $\begin{array}{l}43 \\
(20 / 23 / 0)\end{array}$ & $38(18 / 20 / 0)$ & $\begin{array}{l}20 \\
(10 / 10 / 0)\end{array}$ & $0(0 / 0 / 0)$ & $0(0 / 0 / 0)$ & $0(0 / 0 / 0)$ & $0(0 / 0 / 0)$ & $\begin{array}{l}\text { Left:1.6V/150Hz/60us case (+) } 7 \\
(-)\end{array}$ \\
\hline & & & & & & & & $\begin{array}{l}\text { Right:3.1V/150Hz/60us case }(+) 2 \\
(-)\end{array}$ \\
\hline \multirow[t]{2}{*}{7} & $\begin{array}{l}56 \\
(24 / 20 / 12)\end{array}$ & $35(16 / 12 / 7)$ & $\begin{array}{l}30 \\
(13 / 10 / 7)\end{array}$ & $\begin{array}{l}25 \\
(11 / 9 / 5)\end{array}$ & $0(0 / 0 / 0)$ & $0(0 / 0 / 0)$ & $0(0 / 0 / 0)$ & $\begin{array}{l}\text { Left:2.9V/130Hz/60us case (+) } 6 \\
(-)\end{array}$ \\
\hline & & & & & & & & $\begin{array}{l}\text { Right:2.05V/130Hz/60us case }(+) \\
4(-)\end{array}$ \\
\hline \multirow[t]{2}{*}{8} & $\begin{array}{l}32 \\
(19 / 13 / 0)\end{array}$ & $20(12 / 8 / 0)$ & $11(8 / 3 / 0)$ & $4(3 / 1 / 0)$ & $0(0 / 0 / 0)$ & $0(0 / 0 / 0)$ & $0(0 / 0 / 0)$ & $\begin{array}{l}\text { Left:2.3V/130Hz/60us case (+) } \\
6(-)\end{array}$ \\
\hline & & & & & & & & $\begin{array}{l}\text { Right:2.3V/130Hz/60us case }(+) 2 \\
(-)\end{array}$ \\
\hline \multirow[t]{2}{*}{9} & $\begin{array}{l}52 \\
(21 / 20 / 11)\end{array}$ & $46(19 / 19 / 8)$ & $\begin{array}{l}25 \\
(12 / 10 / 3)\end{array}$ & $16(8 / 5 / 3)$ & $3(2 / 1 / 0)$ & $3(2 / 1 / 0)$ & $3(2 / 1 / 0)$ & $\begin{array}{l}\text { Left:2.5V/130Hz/60us case (+) } 8 \\
(-)\end{array}$ \\
\hline & & & & & & & & $\begin{array}{l}\text { Right:2.5V/130Hz/60us case }(+) 3 \\
(-)\end{array}$ \\
\hline
\end{tabular}

Table 2. TWSTRS scores at baseline and after bilateral STN DBS. TWSTRS-Toronto Western Spasmodic Torticollis Rating Scale, STN-subthalamic nucleus, DBS-deep brain stimulation. 


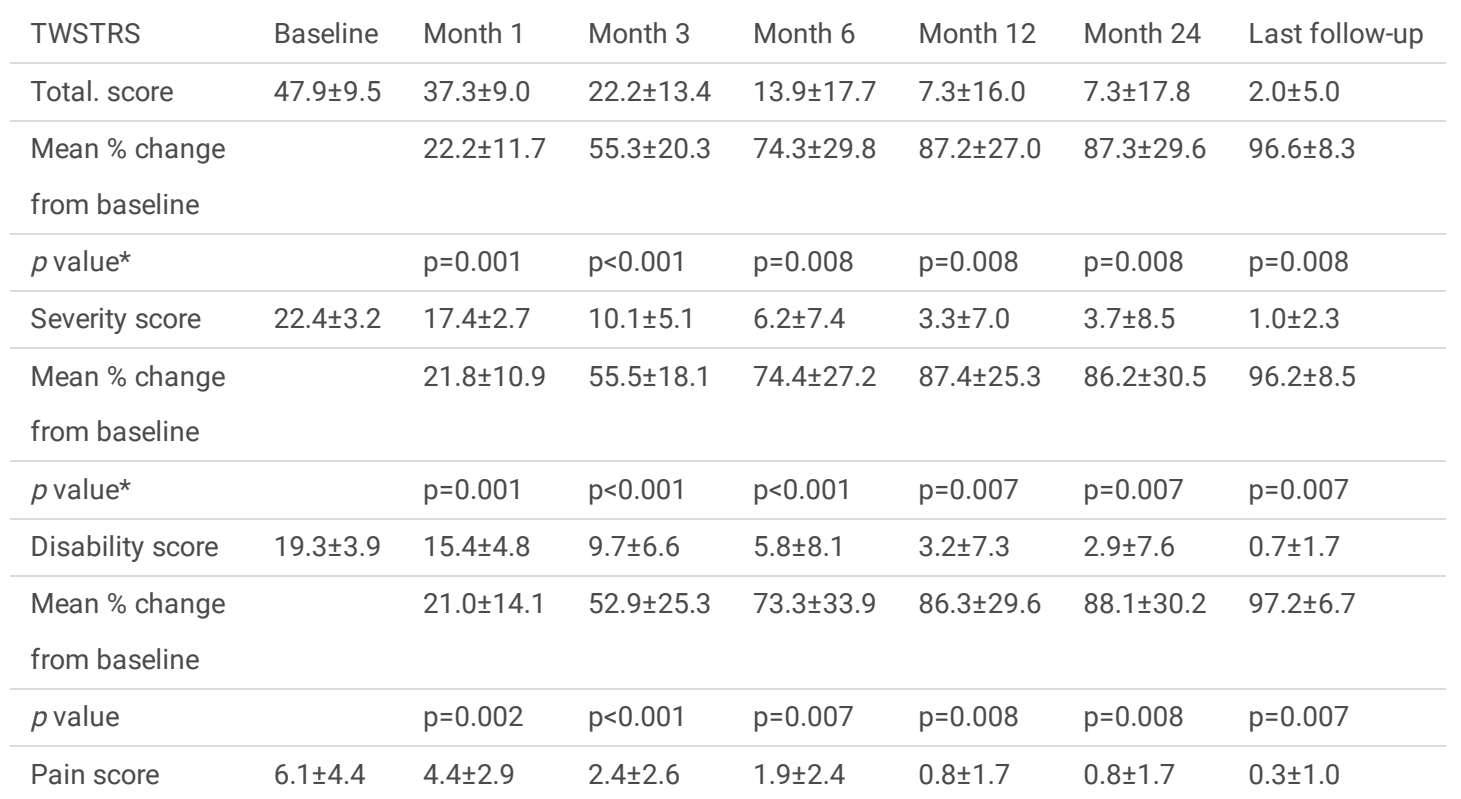

Table 3. The outcomes for TWSTRS and improvement from baseline. TWSTRS-Toronto Western Spasmodic Torticollis Rating Scale

Mean values are expressed \pm SD

* $p$ values for improvement comparisons between baseline and follow-up time points after operation, as assessed using two tailed paired-sample t-tests or Wilcoxon matched-pairs signed-rank tests.

\begin{tabular}{llll}
\multirow{2}{*}{ SF-36 Subscale } & \multicolumn{2}{l}{ Score (Mean \pm SD) } & \multirow{2}{*}{$p$ value } \\
\cline { 2 - 3 } & Baseline & Last follow-up & \\
\hline General health & $16.1 \pm 4.2$ & $72.6 \pm 20.7$ & $p=0.008$ \\
\hline Physical functioning & $33.3 \pm 18.4$ & $90.0 \pm 14.1$ & $p=0.007$ \\
\hline Role physical & $13.9 \pm 13.2$ & $86.1 \pm 18.2$ & $p=0.006$ \\
\hline Role emotional & $25.9 \pm 22.2$ & $88.9 \pm 23.6$ & $p<0.001$ \\
\hline Social functional & $27.7 \pm 23.1$ & $85.9 \pm 15.8$ & $p=0.008$ \\
\hline Body pain & $44.2 \pm 19.9$ & $90.0 \pm 10.0$ & $p<0.001$ \\
\hline Vitality & $26.1 \pm 9.6$ & $70.0 \pm 14.6$ & $p=0.008$ \\
\hline Mental health & $22.2 \pm 7.8$ & $72.9 \pm 11.5$ & $p=0.007$
\end{tabular}

Table 4 The outcomes for 36-item Short-Form General Health Survey. SF-36-The 36-item Short-Form General Health Survey, SD-standard deviation.

\section{Figures}




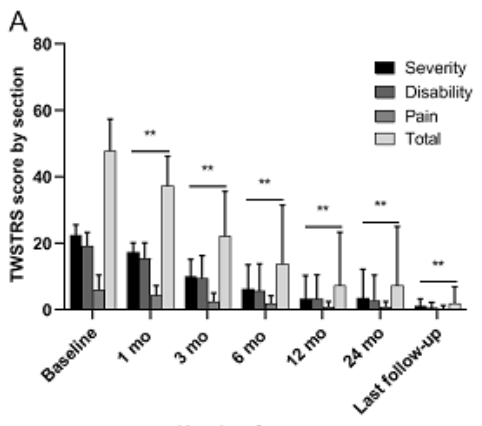

Months after surgery

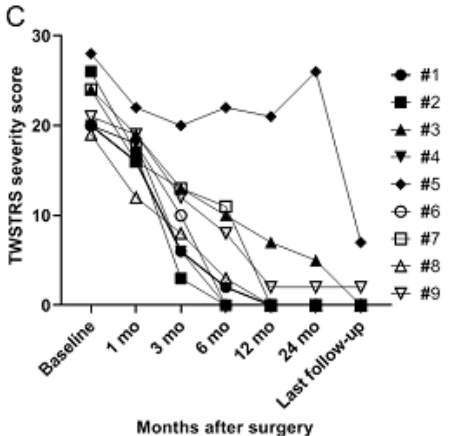

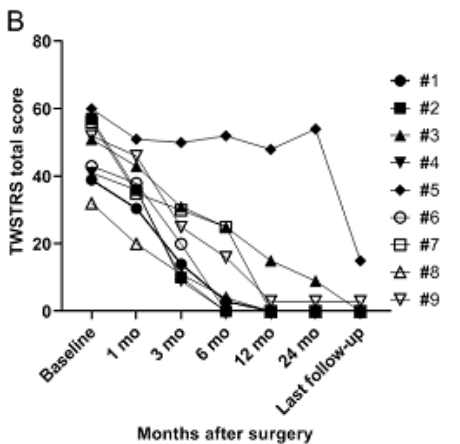

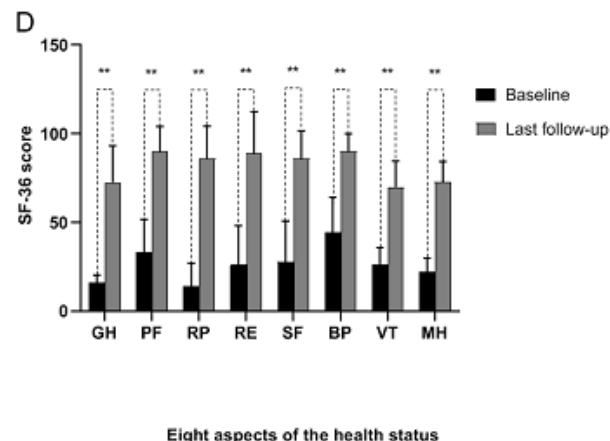

\section{Figure 1}

Mean score for TWSTRS severity, disability, pain, and total scores at various time points before (baseline) and after operation $\mathbb{A} \mathrm{A}$. Line graphs show individual scores of the TWSTRS total score (B) and severity score (C) at various time points before (baseline) and after operation. Mean score for the baseline and the

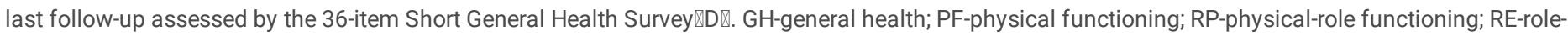
emotional functioning; SF-social functioning; BP-bodily pain; VT-vitality; MH-mental health. ${ }^{\star *} \mathrm{p}<0.01$.

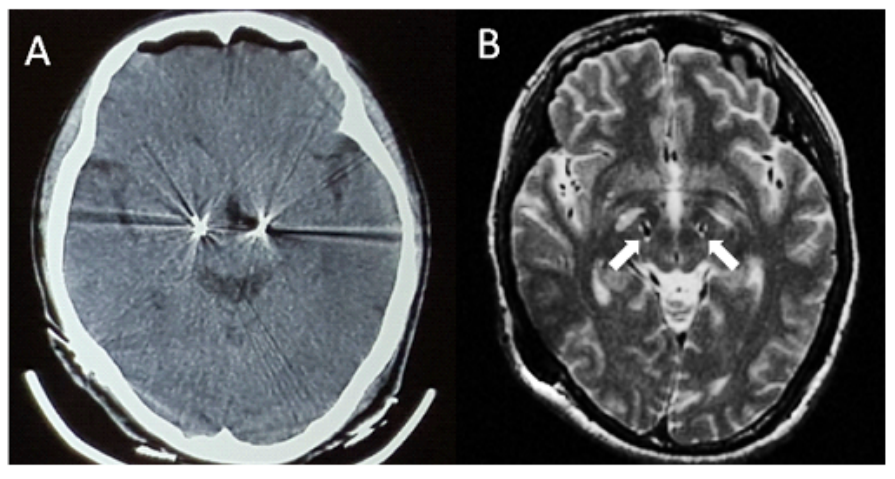

Figure 2

Case 4. Postoperative brain CT (A) for ruling out haemorrhage and axial T2-weighted MR images (B) for showing the targets location (white arrow) of the subthalamic nucleus. 